\title{
EMPREGO, RENDA E INFORMALIDADE: UM ESTUDO DA FEIRA DA CIDADE EM ANANINDEUA (PA)
}

\author{
José Raimundo Trindade ${ }^{1}$ \\ Ewerton Uchoa Fiel ${ }^{2}$
}

RESUMO: Este artigo analisa as principais características das relações informais de trabalho, enfocando um perfil muito especifico de trabalhador (a): o (a) feirante. A Feira é um lugar de burburinho, sendo que as cidades modernas sãos espaços de aglomeração, constituindo as feiras espaços não somente de comercialização, mas também de interação e sociabilidade diversa. Nestes mercados se combinam características de economia mercantil simples (EMS) e economia mercantil capitalista (EMC), onde se encontram uma grande variedade de mercadorias e serviços. As hipóteses admitidas são duas, a primeira discorre sobre a afirmação de que as relações de trabalho informal nas feiras do município de Ananindeua influem positivamente no mercado de trabalho local ao gerar empregos, renda, consumo de subsistência. A segunda trata de que, para o feirante de Ananindeua que trabalha por conta própria, migrar do setor informal para o setor formal não é uma opção vantajosa, devido a precariedade do emprego formal aliada à dificuldade de inserção destes no mercado por motivos diversos, idade, escolaridade, baixa rentabilidade do negócio, além dele possuir o sentimento de propriedade como forte fator subjetivo, dentre outros. $\mathrm{O}$ artigo encontra-se dividido em três seções. Inicialmente faz-se uma descrição e caracterização do trabalho do feirante, assim como sua interatividade com os processos de reprodução social; na seção seguinte trata-se da informalidade como um padrão regular de ocupação e geração de renda; por fim, aborda-se e se problematiza a precariedade das relações de trabalho do feirante e como ela se engendra aos mecanismos de superexploração e aviltamento das relações de trabalho próprias do mundo periférico brasileiro.

Palavras-chave: Informalidade; Feirante; Relações de Trabalho.

ABSTRACT: This article analyzes the main characteristics of informal labor relations, focusing on a very specific profile of worker: the marketer. The Fair is a place of buzz, and modern cities are spaces of agglomeration, the fairs being spaces not only for commercialization, but also for interaction and diverse sociability. These markets combine characteristics of simple market economy (EMS) and capitalist market economy (EMC), where a wide variety of goods and services are found. The admitted hypotheses are two, the first one is about the affirmation that the informal labor relations in the fairs of the municipality of Ananindeua positively influence the local labor market by generating jobs, income, subsistence consumption. The second is that, for the Ananindeua marketer who works on his own, migrating from the informal sector to the

\footnotetext{
Professor Associado vinculado ao PPGE/UFPA. Universidade Federal do Pará. E mail: jrtrindade@uol.com.br.

${ }^{2}$ Graduação em Economia - Universidade Federal do Pará. E-mail: ewertonufv@gmail.com.
} 
formal sector is not an advantageous option, due to the precariousness of formal employment combined with the difficulty of inserting them into the market for various reasons, age, education, low profitability of the business, in addition to having the feeling of ownership as a strong subjective factor, among others. The article is divided into three sections. Initially, a description and characterization of the marketer's work is done, as well as its interactivity with the processes of social reproduction; the next section deals with informality as a regular pattern of occupation and income generation; finally, the precariousness of the marketer's labor relations is approached and problematized and how it engenders the mechanisms of overexploitation and degradation of labor relations typical of the Brazilian peripheral world.

Keywords: Informality; Marketer; Work relationships.

\section{INTRODUÇÃO}

Este artigo analisa as principais características das relações informais de trabalho, enfocando um perfil muito especifico de trabalhador (a): o (a) feirante. A Feira é um lugar de burburinho (STORPER E VENABLES, 2005, p. 53), sendo que as cidades modernas sãos espaços de aglomeração nas quais "acontecimentos diferentes e (...) diversos" se processam a uma crescente velocidade, constituindo as feiras espaços não somente de comercialização, mas também de interação e sociabilidade diversa.

Nestes mercados se combinam características de economia mercantil simples (EMS) e economia mercantil capitalista (EMC), onde se encontram uma grande variedade de mercadorias e serviços, desde vestuário a produtos alimentícios, serviços gerais, como consertos de utensílios domésticos, até a oferta de serviços mais complexos, inclusive concorrentes do setor formal. $O$ feirante é todo aquele que pratica atos de comércio de bens ou venda serviços, com vistas à obtenção de renda para 0 seu sustento e tem o comércio de mercadorias como meio de subsistência e obtenção de rendimento, sendo um dos intermediadores entre fornecedores e o consumidor final que frequenta às feiras, os fregueses (QUEIROZ, 2015).

A análise desenvolvida resultou de uma pesquisa de campo na "Feira da Cidade" no município de Ananindeua Pará, na Região Metropolitana de Belém. A Feira da Cidade é fruto de uma intervenção do governo municipal frente à demanda pela desobstrução de trechos da Avenida Arterial 18 e ruas adjacentes do Conjunto 
Residencial Cidade Nova IV. Os feirantes que foram remanejados ao novo local faziam parte da "Feira do Quatro", a sua inauguração foi em 2006.

A justificativa do projeto de construção visava o estabelecimento de um modelo padrão para esses mercados locais, oferecendo mais segurança e conforto para os trabalhadores e para o público frequente, o que de fato, ocorreu (MEMORIAL, 2005). Todavia, a mudança de localidade gerou algumas dificuldades aos feirantes, alguns não conseguiram se adaptar à nova freguesia e ao modelo de feira regular e fixa, pois uma alteração territorial mesmo que aparentemente pouco significativa tem grande impacto na preferência do consumidor de frequentar ou deixar de ir naquele espaço.

\section{FIGURA 1 - Feira da Cidade visão do alto}

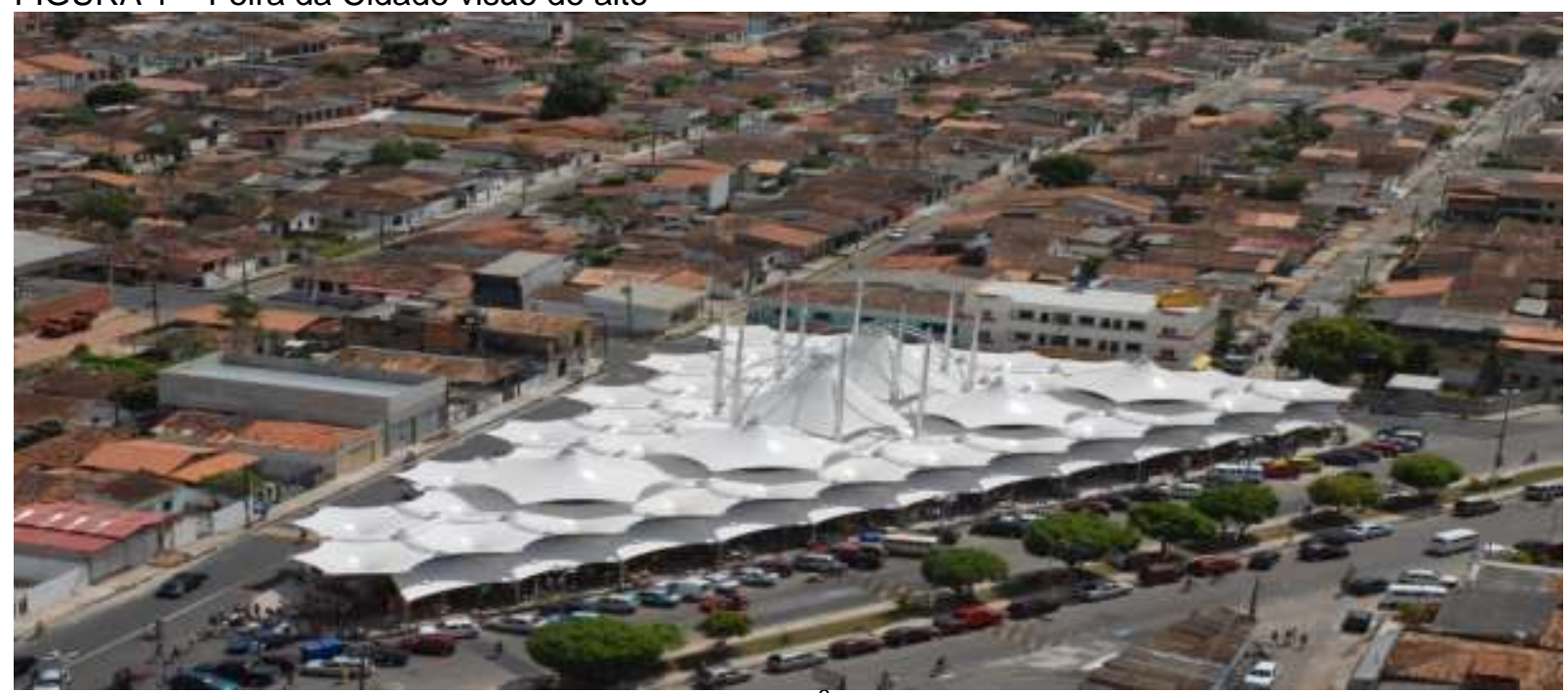

Fonte: Blog Meia Dois Nove, arquitetura e consultoria ${ }^{3}$

A noção de informalidade adotada entende a feira e seus agentes como integrantes de uma relação mais ampla que o mercado de trabalho assalariado convencional ou normal (celetista e estatutário), constituindo um padrão não totalmente regular ou capitalista de relações econômicas, onde prevalecem os contratos (acordos) informais entre os indivíduos que interagem com o setor formal e com o poder público sob a lógica capitalista.

As relações de trabalho no setor informal neste artigo abrangem os trabalhadores feirantes do município de Ananindeua (PA), sendo entendidas, sobretudo

${ }^{3}$ https://goo.gl/EL8EYa. Acessado em 21/02/2018, às 17:18 pm. 
como relações de trabalho que não seguem o padrão de assalariamento formal, compondo o setor informal da economia (SI). Neste segmento, os acordos são feitos entre as partes interessadas, geralmente o proprietário do negócio (que pode ser tanto uma microempresa, Microempreendedor Individual - MEI, como uma barraca de lanche) e o trabalhador, que pode ser um particular ou membro familiar. Os agentes do SI que serão tratados visando alcançar o objetivo desta pesquisa são: os trabalhadores assalariados sem registro e os autônomos (conta própria), que pode ser tanto proprietário de um negócio como trabalhador individual prestador de serviços (CACCIAMALI, 2000).

Estabelecemos três ordens de relações categoriais para se entender a informalidade. Considerando o entendimento marxista, GONZÁLEZ (1977, p. 21) define alguns parâmetros de diferenciação da economia mercantil simples e da economia mercantil capitalista em cinco pontos: i) na EMC existe uma mercadoria especial que não está presente na EMS: a força de trabalho, cuja condição é o assalariamento enquanto padrão de exploração; ii) a EMS tem um caráter secundário e subordinado, a EMC tem um caráter geral e dominante; iii) a EMS baseia-se na pequena propriedade dos meios de produção, enquanto a EMC baseia-se na grande propriedade capitalista sobre os meios de produção; iv) na EMS o proprietário dos meios de produção e o produtor direto são uma e única pessoa, ou parte de uma relação familiar; enquanto na EMC, o central é a relação assalariada e a exploração do trabalho alheio, por fim; v) a lógica imediata da EMS é a satisfação das necessidades (subsistência), enquanto na EMC é a obtenção da mais-valia, do lucro.

A feira enquanto atividade informal combina parcialmente condições econômicas de formas mercantis simples, portanto, fundadas em condições somente de reprodução simples dos trabalhadores, que pode ser representado formalmente pela troca entre a mercadoria força de trabalho (FT) e mercadorias de subsistência ou reprodução do trabalhador (M), mediada por uma relação monetária (D); porém também vicejam formas não propriamente capitalistas, contudo com a presença de relações de trabalho de subordinação familiar ou mesmo de emprego assalariado flexível. Esses agentes econômicos de economia mercantil simples se relacionam com empresas fornecedoras que são tipicamente capitalistas, pelo menos uma parte destas; outra parcela também 
se refere a produtores não propriamente capitalistas, como por exemplo, agricultores familiares e pequenos produtores artesãos.

Um terceiro elemento categorial central refere-se a relação de menores gastos de circulação das mercadorias ofertadas no ambiente da feira. Como os gastos de circulação são um custo fixo para os capitalistas diversos produtores das mercadorias, a feira e suas condições menos custosas de emprego, seja pelas intensivas jornadas de trabalho, seja pelo emprego de trabalho familiar, seja pela disponibilidade do capital fixo (box, balanças, automóveis para deslocamento das mercadorias, etc.) de propriedade ou posse dos próprios feirantes ou cedidos pelo Estado, possibilita que a mais-valia se realize em condições comerciais menos custosas ao capital.

Os ganhos dos feirantes, portanto, constitui uma parcela dos gastos comerciais que haveria caso o capitalista propriamente tivesse que arcar com tais despesas, porém aparece aqui atenuado pelas condições de espoliação destes trabalhadores. Uma segunda parcela de ganhos deve-se a transferência de excedentes econômicos dos setores não capitalistas envolvidos no processo de produção das mercadorias, em especial os camponeses ou agricultores familiares cedem uma parcela dos seus ganhos econômicos (excedentes) para que se tenha realizado o valor das suas mercadorias.

Figura 2 - Cotidiano da Feira da cidade

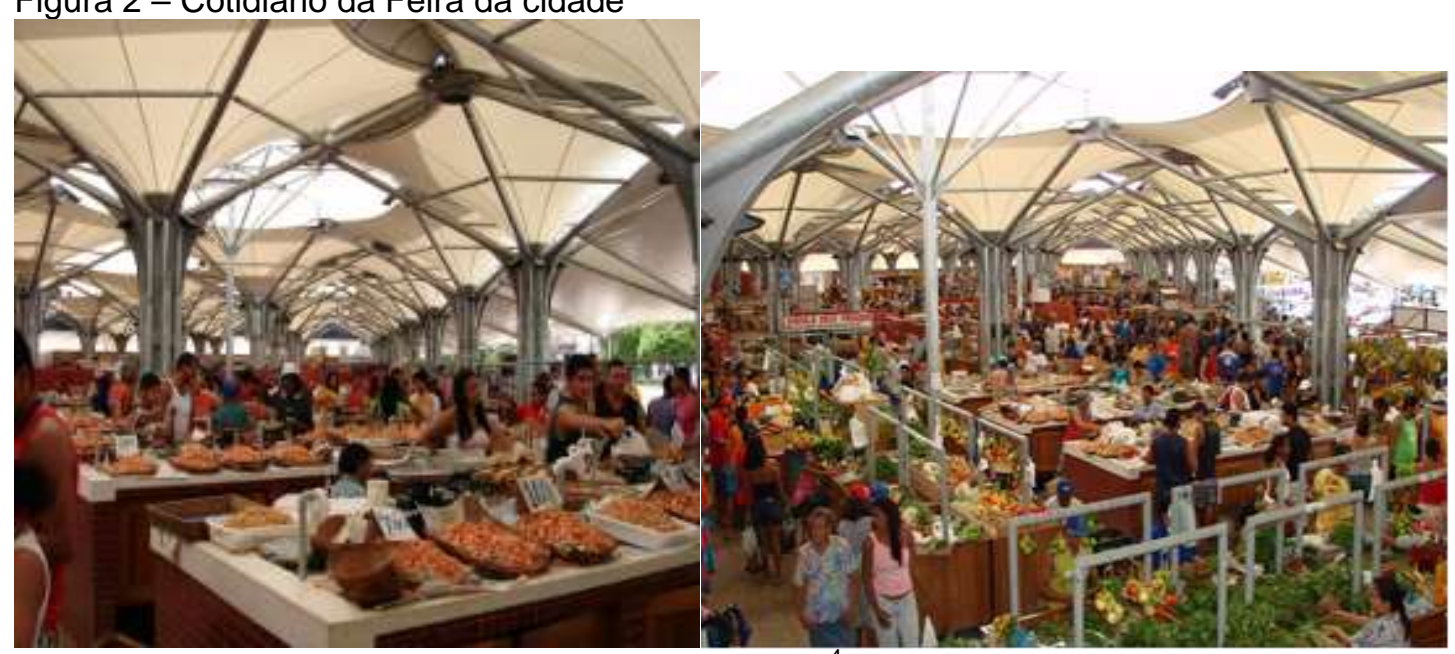

Fonte: blog meia dois nove, arquitetura e consultoria ${ }^{4}$

${ }^{4}$ https://goo.gl/R1c5as. Acessado em 21/02/2018, às 17:18 pm. 
A pesquisa se realizou com a aplicação de perguntas semiestruturadas, foram aplicados 29 (vinte e nove) formulários com o intuito de verificar o funcionamento desse sistema de mercado popular, expor as principais características dos trabalhadores e como se desenvolve as relações de trabalho neste ambiente, além de mostrar a importância social e econômica desses pequenos negócios para a economia local. Às análises foram feitas com base em entrevistas e no preenchimento do formulário contendo 44 perguntas.

O feirante não é um produtor, mas é um dos intermediários entre o produtor e o consumidor final, salvo em casos mais específicos ${ }^{5}$. Esses trabalhadores podem ser denominados pelo seu produto de venda, ou seja, peixeiro; açougueiro; fruteiro e assim por diante. $O$ feirante pode ser o patrão ou dono do negócio, contratado pelo dono ou ser coparticipante do negócio como membro familiar. Neste ambiente predomina os acordos informais ${ }^{6}$, às relações de trabalho e os contratos são feitos entre os feirantes diretamente (SENA, 1999; 2002).

Esse segmento da economia informal possui dentre suas características a desorganização política e jurídica ${ }^{7}$, além de baixo grau de escolaridade, como se descreverá mais a frente. Eles despendem sua força de trabalho em condições muito precárias, perfil típico de um trabalhador de feiras populares, feira coberta, e feira de rua (QUEIROZ, 2015; CACCIAMALI, 2000; SENA, 2002).

Consideramos a feira como local de relações econômicas que precisa ser mais bem estudada, para isso faz-se uma breve descrição deste ambiente de trabalho, considerado de elevada complexidade e de alta relevância para a investigação econômica. Considera-se o objetivo central do artigo investigar as condições econômicas e sociais do trabalho informal em feiras no município de Ananindeua, buscando estabelecer as condições de funcionamento, a geração de renda e empregos e as interações com o chamado setor forma do mercado de trabalho.

As hipóteses admitidas são duas, a primeira discorre sobre a afirmação de que as relações de trabalho informal nas feiras do município de Ananindeua influem

\footnotetext{
${ }^{5}$ Produtor de hortaliças e trabalhos artesanais é um pouco comum a depender da feira.

${ }_{7}^{6}$ Acordos informais podem ser verbais e dependem da vontade entre as partes.

${ }^{7}$ Ver Dimensões da informalidade em Belém, Sena, Laura 1999, p.194. Novos cadernos do NAEA v. 2, $\mathrm{n}^{\circ} 2$
} 
positivamente no mercado de trabalho local ao gerar empregos, renda, consumo de subsistência. A segunda trata de que, para o feirante de Ananindeua que trabalha por conta própria, migrar do setor informal para o setor formal não é uma opção vantajosa, devido a precariedade do emprego formal aliada à dificuldade de inserção destes no mercado por motivos diversos, idade, escolaridade, baixa rentabilidade do negócio, além dele possuir o sentimento de propriedade como forte fator subjetivo, dentre outros.

$\mathrm{O}$ artigo encontra-se dividido em mais três seções, além desta introdução. $\mathrm{Na}$ seção seguinte faz-se uma descrição e caracterização do trabalho do feirante, assim como sua interatividade com os processos de reprodução social; na terceira seção trata-se da informalidade como um padrão regular de ocupação e geração de renda; por fim, na quarta seção aborda-se e se problematiza a precariedade das relações de trabalho do feirante e como ela se engendra aos mecanismos de superexploração e aviltamento das relações de trabalho próprias do mundo periférico brasileiro.

\section{O LOCAL DE TRABALHO E AS CONDIÇÕES DE REPRODUÇÃO SOCIAL DOS TRABALHADORES DA FEIRA DA CIDADE}

Concernente ao local de trabalho, $90 \%$ deles afirmou serem os donos do estabelecimento na Feira da Cidade. Na Tabela 1 fica evidenciada uma característica importante na Feira em análise, o fato de que a maioria dos feirantes eram proprietários do negócio, sendo que a amostra com base na técnica de amostragem de população finita (LUCHESA, 2011) de 29 feirantes abrangeu entre 8 a 10\% do total de trabalhadores, sendo significativa para revelar tal peculiaridade, com precisão de $5 \%$.

Questionados sobre como conseguiram a vaga para exercer suas atividades na Feira, $87 \%$ dos entrevistados responderam que tinham pontos comerciais na antiga "Feira do Quatro IV". Como já descrito, essa feira ficava na divisa da avenida arterial 18 em Ananindeua, e por efeito de remanejamento, os feirantes receberam na Feira da Cidade boxes e pontos comerciais de acordo com os seus padrões anteriores ${ }^{8}$.

\footnotetext{
${ }^{8}$ Nesse processo, é salutar dizer que, alguns dos feirantes a beira da rua, foram muito beneficiados e outros prejudicados, por conta das mudanças muitos feirantes não conseguiram manter seus negócios, precisando sair de seus estabelecimentos por meio da venda. Para maiores detalhes, conferir o estudo monográfico de FIEL (2018).
} 
A Feira da Cidade foi inaugurada em novembro de 2006, sendo que $69 \%$ dos feirantes declararam desenvolver suas atividades a mais de 10 anos e $21 \%$ a mais de 5 anos. Estes dados expressam uma significativa permanência destes trabalhadores nesta atividade, definindo um padrão de grande regularidade na atividade informal sob o ponto de vista de manutenção das condições de reprodução física e social destes trabalhadores.

O aspecto central referente à segurança da posse sobre o espaço físico de realização das atividades, evitando a subordinação à fiscalização indevida e a insegurança visível nos trabalhadores de ruas ou feiras irregulares, como relatado no estudo de Sena (2002), Queiroz (2015) e no Mapa do Trabalho Informal em São Paulo, estabelece uma lógica menos submetida a riscos de perda dos meios de produção básicos de propriedade destes trabalhadores autônomos.

O trabalho na feira apesar de difícil é apreciado por $97 \%$ dos feirantes, que declaram que "gostam de seus trabalhos na feira". A análise sobre a permanência e transição dos trabalhadores feirantes demonstra que $55 \%$ dos entrevistados responderam que tinham empregos anteriores na economia formal (Tabela 3), apenas $10 \%$ responderam que gostariam de regressar aos seus respectivos empregos no setor formal, fortalecendo o argumento de que para esse seguimento o emprego formal não apresenta estimulo suficiente para o abandono das atividades na Feira.

Ao que diz respeito a Prefeitura Municipal de Ananindeua (PMA), os feirantes demonstraram não estar satisfeitos com a Prefeitura, 69\% afirmam que a administração da feira é ruim, $21 \%$ regular e $10 \%$ Boa. Questionados com relação a sugestões de melhoria, $48 \%$ disseram que a Feira da Cidade precisa de manutenção frequente, 38\% levantaram a ideia de que a administração da Feira é ruim e precisa ser melhorada, colocando funcionários que "lidem melhor com os feirantes".

A relação da informalidade com o Estado, representada aqui pela PMA, se estabelece condicionada por quatro aspectos que são denotados na pesquisa: i) a infraestrutura social (ambiente construído) possibilitado pela ação do Estado; ii) regras de convívio e de interação entre os feirantes e os funcionários administrativos da feira; iii) regras de interação entre os feirantes e os consumidores; iv) papel de regramento legal e de segurança pública. 
Os feirantes ao tratarem como ruim a gestão municipal apontam os limites da relação entre o Estado e estes trabalhadores, sendo fundamental observar que a mediação do poder estatal constitui uma relação indireta, porém centro da continuidade das relações informais. $O$ trabalho assalariado normal tem na base contratual capitalista o centro de regulação, sendo o Estado um agente político atuando somente secundariamente.

Vale ressaltar que o trabalho informal nas feiras possui suas peculiaridades, não sendo adequado generalizar tais relações com o mercado de trabalho informal de Ananindeua como um todo ou para outras categorias de trabalhadores deste setor. A temática da informalidade é um fenômeno vasto de relações e de alta complexidade econômica e social.

A Tabela 1 mostra as características pessoais de vida e trabalho dos feirantes, a maior parte dos feirantes entrevistados está na faixa etária de 36 a 55 anos, têm-se um total de $62 \%{ }^{9}$ de feirantes com até 55 anos. A segunda maior faixa é a dos que possuem mais de 56 anos, representando $24 \%$ dos entrevistados. Nota-se que grande proporção dos feirantes apresenta uma faixa etária elevada, explicável pela dificuldade de obtenção das condições básicas para sustentação do micro negócio, próprio de uma EMS, garantindo uma renda básica para subsistência e manutenção do negócio, somente acumulado recursos necessários ao longo de certo período de tempo.

\footnotetext{
${ }^{9}$ Neste ponto, a pesquisa feita em 97 por Sena, 2002, foi um pouco divergente quanto a idade dos trabalhadores informais. Os ambulantes com até 39 anos representavam mais da metade do universo pesquisado pela autora.
} 
Tabela 1 - Quem são os feirantes

\begin{tabular}{|c|c|c|c|c|c|c|c|c|c|c|c|c|c|c|c|c|c|c|c|}
\hline Idade & $\%$ & $s$ & $\%$ & IIT & $\%$ & ON & $\%$ & EC & $\%$ & PF & $\%$ & $\mathbf{F}$ & $\%$ & QF & $\%$ & RC & $\%$ & C & $\%$ \\
\hline $\begin{array}{l}15 a \\
25\end{array}$ & 3 & $F$ & 48 & $\begin{array}{l}\text { Menos } \\
\text { de } 10 \\
\text { anos }\end{array}$ & 28 & Belém & 41 & Solteiro & 31 & Mant & 59 & Sim & 90 & $\begin{array}{l}1 a \\
2\end{array}$ & 41 & Sim & 69 & Pai & 3 \\
\hline $\begin{array}{l}26 \mathrm{a} \\
35\end{array}$ & 10 & $M$ & 52 & $\begin{array}{l}\text { Entre } \\
10 \mathrm{a} \\
15\end{array}$ & 52 & $\begin{array}{l}\text { Interior } \\
\text { do } \\
\text { Estado }\end{array}$ & 31 & Casado & 66 & Comp & 41 & Não & 10 & $\begin{array}{l}3 a \\
4\end{array}$ & 41 & Não & 31 & Cônjuge & 38 \\
\hline $\begin{array}{l}36 a \\
45\end{array}$ & 31 & & & $\begin{array}{l}\text { Entre } \\
16 \mathrm{a} \\
20\end{array}$ & 17 & $\begin{array}{l}\text { Outro } \\
\text { Estado }\end{array}$ & 28 & Outro & 3 & & & & & $\begin{array}{l}5 a \\
6\end{array}$ & 3 & & & $\begin{array}{l}\text { Filhos } \\
\text { (a) }\end{array}$ & 17 \\
\hline $\begin{array}{l}46 a \\
55\end{array}$ & 31 & & & $\begin{array}{l}\text { Mais } \\
\text { de } 20 \\
\text { anos }\end{array}$ & 3 & $\begin{array}{l}\text { Outro } \\
\text { País }\end{array}$ & 0 & & & & & & & $\begin{array}{l}\text { Mais } \\
\text { de } 6\end{array}$ & 3 & & & Outro & 10 \\
\hline $\begin{array}{l}\text { Mais } \\
\text { de } 56\end{array}$ & 24 & & & & & & & & & & 100 & & 100 & & 88 & & 100 & & 68 \\
\hline Total & 100 & & 100 & & 100 & & 100 & & 100 & & 100 & & 100 & & 88 & & 100 & & 68 \\
\hline
\end{tabular}

Fonte: Pesquisa direta. Elaboração própria.

* Dados arredondados

RC - Renda complementar

IIT - Idade de inserção no trabalho

ON - Onde nasceu

EX - Estado civil

PF - Posição na família

S-Sexo

Mant - Mantenedor

Comp. Complementar

F - Filhos

Outro fator a ser considerado refere-se ao quadro precário de reprodução social, constata-se que $28 \%$ destes trabalhadores começaram a trabalhar com menos de 10 anos de idade e 52\% entre 10 e 15 anos. Por serem mais flexíveis quanto à utilização de mão de obra, comportam até mesmo trabalho infantil familiar (VEDANA, 2004, p. 200) como condição da própria dinâmica econômica precária (QUEIROZ, 2015; CACCIAMALI, 2000; SENA, 2002).

Sobre a procedência desses trabalhadores, $41 \%$ são naturais de Belém, porém percebe-se a elevada procedência interiorana $(31 \%)$ ou de outros estados $(28 \%)$, denotando o elevado fluxo migratório e a especifica condição da economia local de não oferecer empregos minimamente satisfatórios, sendo o trabalho nas feiras uma saída possível de sobrevivência. A migração das regiões menos dinâmicas ainda é uma realidade nos anos recentes e revela a falta de empregos nos seus municípios de 
origem, implicando em um movimento migratório para onde tenha mais oportunidades e trabalho (THEODORO, 2005; SENA, 2002; CACCIAMALI, 2000).

A análise das características familiares demarcam outros aspectos, o primeiro refere-se ao peso da atividade na renda familiar, observando-se que $59 \%$ dos feirantes se declaram como chefes ou mantenedores da família e $69 \%$ do total afirmam unir as rendas com outros membros familiares como complemento à renda necessária ao sustento familiar e um segundo aspecto é o peso considerável da presença feminina (48\%), reforçando a percepção de que as atividades informais são uma combinação de relações não contratuais e relações familiares, tendo grande importância a capacidade feminina de gestar os pequenos negócios característicos da atividade feirante.

Tabela 2 - Nivel de escolaridade dos feirantes

\begin{tabular}{l|c|c|c}
\hline \multirow{2}{*}{ Escolaridade } & \multirow{2}{*}{$\%$} & \multicolumn{2}{|c}{ Ainda estuda } \\
\cline { 3 - 4 } & & Sim & Não \\
\hline $1^{\circ}$ grau incompleto & 24 & - & 24,13 \\
\hline $1^{\circ}$ grau completo & 17 & - & 17,24 \\
\hline $2^{\circ}$ grau incompleto & 0 & - & - \\
\hline $2^{\circ}$ grau completo & 45 & 3,44 & 41,37 \\
\hline $3^{\circ}$ grau incompleto & 3 & 3,44 & - \\
\hline $3^{\circ}$ grau completo & 10 & 6,89 & 3,44 \\
\hline Total & $\mathbf{1 0 0}$ & $\mathbf{1 3 , 7 7}$ & $\mathbf{8 6 , 1 8}$ \\
\hline
\end{tabular}

Fonte: pesquisa direta, elaboração própria. Dados aproximados.

Quanto à escolaridade (Tabela 2), constatou-se que $45 \%$ dos feirantes possuem o ensino médio completo, $10 \%$ possuem formação superior, 3\% têm o superior incompleto em andamento e $24 \%$ com apenas o fundamental. Esses resultados apresentam certa melhoria do nível de instrução dos trabalhadores feirantes da Feira da Cidade em Ananindeua, se comparados aos dados de outras pesquisas como a de Rocha, et al. $^{10}$ (2010) e de Godoy (2007), que tratam do perfil socioeconômico dos trabalhadores de feiras livres no Rio Grande do Sul (RS), e afirmam que o grau de escolaridade dos feirantes em sua maioria é o fundamental. No trabalho Economia Informal Urbana (IBGE, 2003), também se constatou que o nível de escolaridade dos trabalhadores informais está entre o fundamental incompleto e médio

${ }^{10}$ Cf. Perfil socioeconômico dos feirantes e consumidores da Feira do Produtor de Passo Fundo, RS. 
completo, com destaque aos trabalhadores por conta própria, 40\% deles tinham apenas o fundamental incompleto.

De modo geral, verificou-se que $86 \%$ dos feirantes abandonaram os estudos. Quando questionados sobre o motivo do abandono escolar a maioria respondeu ser de família muito humilde e que precisavam trabalhar para ajudar no sustento familiar. Sena (2002, p. 135), constatou que um dos motivos para que os trabalhadores do setor informal terem baixa instrução está ligada a necessidade de inserção precoce no mercado de trabalho, o que Ihes reduzia o tempo de estudos, culminando em abandono escolar ou descontinuidade. O que fica reforçado pelos dados obtidos, já que grande maioria declarou que iniciou a trabalhar com menos de 15 anos (80\%).

\section{A INFORMALIDADE NA FEIRA COMO UM PADRÃO REGULAR DE OCUPAÇÃO E GERAÇÃO DE RENDA}

O Quadro 1 a seguir, estrutura uma série de questões fundamentais para interpretação das condições sociais e econômicas da informalidade de feira. Consideramos que o formato expresso neste quadro nos dá uma percepção de "informalidade regular", ou seja, a permanência continua na informalidade não tendo, por diversas razões, interesse de estabelecer padrões contratuais mais regulares, mais fixos ou num sistema de contratação plenamente subordinada ao assalariamento típico.

Dos feirantes entrevistados, 55\% eram assalariados em seus empregos anteriores, 3\% declararam que eram diarista ou mensalista, porém a grande maioria (75,9\%) já exerce a atividade de feirante por mais de dez anos e não pretende deixar a ocupação atual (79\%). Apenas 3,45\% responderam estar somente até 2 anos como feirante, esses trabalhadores não eram proprietários do negócio e estavam à procura de outro emprego. Evidenciando o fato de que quando o feirante não é o proprietário nem trabalhador familiar à tendência dele é sair em busca de novas oportunidades, sendo para estes o trabalho na feira temporário e reflexo das dificuldades de reinserção no mercado de trabalho formal. Muito embora, esse posicionamento não seja o da maioria.

Os rendimentos no antigo emprego variavam de 1 a 5 salários mínimos, sendo que $45 \%$ ganhavam de 1 a 2 salários mínimos e 10\% ganhavam de 3 a 5 . Percebe-se 
que $55 \%$ dos feirantes tiveram experiências no setor formal, mas que por algum motivo se inseriram no setor informal. A saída do trabalho formal é estabelecida, curiosamente, pelo próprio trabalhador enquanto responsabilidade sua, cuja explicação se dá com base na adaptação no emprego ou na incapacidade pessoal de se envolver na atividade, demonstrando o quanto os aspectos ideológicos e de controle social são fortes. Porém, vale observar que o número de trabalhadores que sempre estiveram em atividades informais é muito elevado (45\%), atestando que o padrão de assalariamento normal nesta realidade nunca se impôs, denotando uma formação social cuja presença de formas flexíveis e precárias nas relações assalariadas convencionais se combinam em diferentes graus as formas econômicas informais.

Como antes atestado por Theodoro (2005, p. 116) as atividades informais resultam de uma conjunção de fatores: i) a extrema desigualdade social, demarcando o contexto social e econômico de baixas oportunidades formais e de seletividade da força de trabalho; ii) a fragilidade do marco regulatório e, depois da LC 13.467/17 (contra reforma trabalhista) a ausência de parâmetros básicos de proteção social e de funcionamento do mercado de trabalho na sua totalidade e; iii) a "capacidade dessas atividades" de se adequarem ao ciclo econômico, "estabelecendo um conjunto de estratégias de alianças e de organização que lhes possibilite (...) a preservação de um espaço de existência". Somem-se a estes aspectos, outros três elementos: iv) a informalidade constitui uma forma estrutural de reprodução de uma parcela dos trabalhadores que dificilmente será incorporada a lógica normativa total do assalariamento; v) constitui um segmento reprodutivo familiar que apresenta dinâmica própria; vi) por fim, a informalidade faz parte dos "faux frais" da circulação, ou seja, gastos de circulação que são improdutivos para o capital, porém fundamentais para realização do valor.

Pode-se, desde a análise da economia de feira tratar da completa imbricação entre formalidade e informalidade, uma conjunção que rompe com a lógica da dualidade que, como demonstrou Oliveira (1988) constituem uma totalidade sociológica e não formações apartadas. 


\begin{tabular}{|c|c|c|c|c|c|c|c|c|c|c|c|}
\hline $\begin{array}{l}\text { Condição do } \\
\text { último } \\
\text { emprego }\end{array}$ & $\%$ & Rendimento & $\%$ & $\begin{array}{l}\text { Deixou o } \\
\text { emprego } \\
\text { formal por }\end{array}$ & $\%$ & $\begin{array}{c}\text { Deixaria a } \\
\text { ocupação } \\
\text { atual }\end{array}$ & $\%$ & \begin{tabular}{|c|} 
Por qual \\
motivo \\
aceitaria \\
trabalhar de \\
carteira \\
assinada \\
\end{tabular} & $\%$ & $\begin{array}{l}\text { Dificuldade } \\
\text { de } \\
\text { reemprego } \\
\text { no setor } \\
\text { formal }\end{array}$ & $\%$ \\
\hline Assalariado & 52 & De 1 a 2 S.M. & 45 & $\begin{array}{l}\text { Motivos da } \\
\text { empresa }\end{array}$ & 24 & Sim & 21 & Maior salário & 41 & $\begin{array}{l}\text { Poucas } \\
\text { vagas }\end{array}$ & 14 \\
\hline $\begin{array}{l}\text { Diarista/ } \\
\text { Mensalista }\end{array}$ & 3 & De 3 a 5 S.M. & 10 & $\begin{array}{c}\text { Motivos } \\
\text { particulares }\end{array}$ & 31 & Não & 79 & $\begin{array}{l}\text { Garantia de } \\
\text { renda fixa }\end{array}$ & 21 & $\begin{array}{l}\text { Exigência de } \\
\text { maior } \\
\text { qualificação }\end{array}$ & 34 \\
\hline ANR & 45 & SRF & 45 & - & - & & & \begin{tabular}{|l|} 
Direitos \\
trabalhistas e \\
proteção \\
legal
\end{tabular} & 17 & $\begin{array}{l}\text { Salários são } \\
\text { baixos }\end{array}$ & 34 \\
\hline & & & & & & & & Outro & 21 & Idade & 18 \\
\hline Total & & & & & & & 100 & & 100 & & 100 \\
\hline
\end{tabular}

Fonte: pesquisa direta, elaboração própria.

*dados aproximados.

*dados de emprego registrado em carteira (CLT)

${ }^{*}$ ANR - Atividade não registrada, estava empregada em atividades informais.

${ }^{*}$ SRF - Sem rendimento fixo.

Os entrevistados que não tinham vínculos empregatícios registrados somaram $45 \%$, esse número não indica que essas pessoas estavam desempregadas, mas que exerciam alguma outra atividade que Ihes garantiam o sustento, porém na condição de informalidade e subocupado. Dos entrevistados empregados no setor formal, $24 \%$ declararam que foram desligados de seu último emprego por motivos da empresa, ou seja, por demissões, falência da empresa, etc. Porém, 31\% disseram que deixaram seu último emprego por motivos particulares, envolvendo insatisfações com o emprego, salário ruim, rigidez da jornada, patrão no ouvido direto, dentre outras, por essas razões tomaram a iniciativa de sair e procurar novos meios de trabalho. Segundo Queiroz (2015) e Cacciamali (2000), tal atitude pode estar relacionada a precarização do 
emprego formal que deixa de ser atrativo a uma parcela da população, que por motivos particulares têm dificuldade de se reempregar ou de encontrar empregos satisfatórios.

Curiosamente ao ser indagado quanto a "gostar ou não do emprego", 48\% dos entrevistados responderam gostar de seu último emprego e apenas 7\% disseram que não. Quando indagados os motivos, $41 \%$ responderam que seria por causa dos direitos e benefícios, como adicional de férias, férias remuneradas e décimo terceiro, porém nenhum deles respondeu que seria por ter um bom salário. Afirmaram ainda "que como feirantes ganhavam mais do que como empregados".

Quando questionados sobre deixar a ocupação de feirante para se empregar como assalariado, $21 \%$ responderam que largariam a feira para voltar ao antigo trabalho. Todavia essa informação deve ser analisada com cautela, em razão de não refletir a subjetividade dos feirantes que são proprietários. Pois os feirantes que sairiam da feira e voltariam ao emprego, em sua maioria eram empregados informais de parentes ou de um particular, não sendo os proprietários do negócio. Os que responderam que não largariam suas ocupações na feira foram bastante expressivo, $79 \%$ declararam que não trocariam o trabalho na feira por um emprego formal registrado. E quando indagados sobre um motivo que os levariam a migrar para o SF, $41 \%$ disseram que seria por um salário maior do que o auferido na feira, 17\% por direitos trabalhistas e proteção legal e $21 \%$ responderam outros motivos. Com efeito, pode-se inferir que o emprego formal não goza de tanto prestígio entre os feirantes, principalmente porque na maioria dos casos não remunera bem os trabalhadores com baixo grau de instrução e idade avançada.

Tabela 3 - Consideração sobre a temporariedade da atividade e principalidade da ocupação

\begin{tabular}{l|c|l|c}
\hline $\begin{array}{l}\text { Considera sua atividade de feirante } \\
\text { como temporária }\end{array}$ & $\%$ & $\begin{array}{l}\text { Feirantes que desempenham outra } \\
\text { ocupação }\end{array}$ & $\%$ \\
\hline Sim & 20,7 & Sim & 20,7 \\
\hline Não & 79,3 & Não & 79,3 \\
\hline Total & $\mathbf{1 0 0}$ & Total & $\mathbf{1 0 0}$ \\
\hline
\end{tabular}

Fonte: pesquisa direta, elaboração própria. Dados aproximados.

A Tabela 03 acima reforça a lógica do trabalho feirante como uma atividade permanente, $79,3 \%$ dos feirantes considera sua atividade como não temporária, assim como se constata que também para $79,3 \%$ dos trabalhadores, a feira representa sua 
principal atividade remunerada. Na pesquisa fica exposto que às dificuldades de acesso ao emprego formal, bem como as peculiaridades intrínsecas dos feirantes (baixo grau de escolaridade, idade avançada), permanecer na feira e no SI é uma condição estrutural e não uma opção.

A pesquisa constatou que dentre os motivos que fariam alguns trabalhadores optarem por deixar as atividades de feirantes: $7 \%$ disseram que gostariam de usufruir dos direitos trabalhistas proporcionados pelo emprego formal; 3,4\% afirmaram que estão ganhando pouco em suas atividades atuais na feira, e 3,4\% revelaram outros motivos. Destaca-se o fato de que nenhum informante mencionou as instalações físicas e as condições do espaço da feira, bastante precária. $O$ total de insatisfeitos com o trabalho na feira é $13,8 \%$, porém, deve-se ressaltar que esse número reverbera a intensão daqueles que não são proprietários do espaço de negócio e que estão na condição de assalariamento informal como opção ao desemprego. Infere-se que para estes, as condições de trabalho e remuneração não podem ser comparáveis aos feirantes proprietários do estabelecimento.

A pesquisa constatou que $55 \%$ dos entrevistados responderam que recebem ajuda de seus familiares (filhos, cônjuge, pai, mãe, etc.) e 11\% disseram que trabalham com outra pessoa não familiar (particular em geral) através de acordos informais estabelecidos entres as partes, sem qualquer intermediação de terceiros, podendo ser rescindido a qualquer tempo o vínculo de contratação, e 34\% alegaram que executam as atividades somente explorando sua própria força de trabalho.

Vale lembrar que Queiroz (2015), argumentou sobre uma espécie de "trabalhadores gratuitos", seu enfoque era basicamente que esse seguimento fazia a circulação das mercadorias como vendedores avulsos. Essa denominação pode ser adequada no seguimento dos trabalhadores por conta própria da feira da Cidade, em função do alto percentual de trabalhadores familiares nos empreendimentos. Leone (2010, p.18) também exorta que os trabalhadores por conta própria são seguidos de uma segunda categoria de trabalhadores não remunerados, que são compostos de familiares. Em geral, os pequenos negócios se utilizam de mão de obra familiar seja em razão da indisponibilidade de capital para contratação, ainda que informal de outrem 
seja pela condição principal do baixo nível de retorno obtido e de reprodução da subsistência familiar.

O mercado de trabalho estando cada vez mais restrito para pessoas com pouca instrução e idade elevada, como é o caso dos feirantes de Ananindeua, que acaba por segregar os trabalhadores e, ao mesmo tempo, os impele para o mercado de trabalho informal, que em algumas ocupações é menos exigente, ao que tange o grau de instrução e a idade, precisando apenas do "saber fazer" as coisas (THEODORO, 2005; QUEIROZ, 2015; SENA, 2002)

Quando questionados sobre as dificuldades que os feirantes enfrentam no trabalho (Quadro 1), 21\% confessaram que as condições físicas da feira são muito precárias. A falta de participação do poder público na manutenção das instalações tornou-se um problema que se prologa desde a sua inauguração. Soma-se a isso, o fato de que não há segurança pública no local, $28 \%$ dos entrevistados afirmaram que o perigo do assalto é constante.

Outros aspectos elencados são as dificuldades de armazenagem e manuseio das mercadoras $(51 \%)$, que também está relacionada de alguma forma com as condições físicas do local de trabalho, principalmente, quando a mercadoria precisa de melhores cuidados de estocagem. É importante acentuar que dentre as dificuldades enfrentadas pelas mulheres, o esforço físico de carregar os produtos foram considerados, o que se equacionaria com equipamentos básicos, como carrinhos e cestas de apoio.

Os feirantes foram indagados sobre que tipos de mudanças ocorreram nos negócios, 59\% responderam que houve aumento na demanda; $24 \%$ que houve redução e $17 \%$ que teria havido aumento na concorrência no espaço da feira. Nota-se que mesmo em períodos de crise e recessão econômica o mercado informal permanece aquecido, isso pode estar atrelado com o fato de que as pessoas buscam utilizar seus recursos reduzidos em produtos básicos e alimentícios, levando a elevação da demanda nas feiras dos bairros populares. Assim consumidores que costumavam "fazer a feira" em supermercados, passam a frequentar as feiras livres, visando obter os mesmos produtos a custos menores. Dos que declaram que as vendas diminuíram, pode-se inferir que se deve a fatores correlacionados com o tipo de mercadoria que 
negociam já que bens de primeira necessidade não saem da cesta de consumo, ainda que sua renda diminua. No entanto, bens supérfluos perdem espaço diante do declínio da renda em momentos de recessão.

\section{A INVISIBILIDADE DE QUASE TUDO: SUPEREXPLORAÇÃO, SUPERJORNADAS, AVILTAMENTO E GANHO DE RENDAS MÍNIMAS}

A jornada de trabalho média diária dos feirantes da Feira da Cidade, conforme seus relatos expressos na Tabela 3 são de 9,2 horas, considerando apenas o tempo que eles passam de fato na feira, do início da organização das atividades até o horário de encerramento. A grande maioria trabalha todos os dias (83\%), sendo que também para $83 \%$ dos feirantes a jornada diária de trabalho é superior a 10 horas. Por sua vez 0 rendimento médio de quase $80 \%$ dos feirantes se localiza na faixa entre 1 a 5 salários mínimos, o que denota às dificuldades e precariedade deste tipo de ocupação. Porém, vale observar que uma parcela de quase $20 \%$ apresenta uma condição de rendimento superior à média, constituindo um segmento com maior estrutura de vendas e que geralmente tem uma relação de fornecimento com setores não capitalistas, o que possibilita certo poder de intermediação e ganho mais elevado que a média.

Tabela 4 - jornada de trabalho e rendimento dos trabalhadores da feira da cidade em ananindeua.

\begin{tabular}{|c|c|c|c|c|c|}
\hline Dias de trabalho & $\%$ & Jornada diária & $\%$ & $\begin{array}{c}\text { Rendimento } \\
\text { Melhor Mês do } \\
\text { Ano } \\
\end{array}$ & $\%$ \\
\hline Segunda a Sexta & 3 & De 4 a 6 horas & 41 & Menos de 1 S.m. & 10 \\
\hline Segunda a Sábado & 14 & De 7 às 10 horas & 42 & De 1 a 2 S.m. & 31 \\
\hline \multirow[t]{2}{*}{ Todos os dias } & 83 & Mais de 10 horas & 17 & De 3 a 5 S.m. & 38 \\
\hline & & & & Mais de 5 S.m. & 21 \\
\hline Total & 100 & & 100 & & 100 \\
\hline
\end{tabular}

Fonte: pesquisa direta, elaboração própria. Dados aproximados.

O trabalho informal exercido na Feira da Cidade possui algumas regras de funcionamento, não se pode omitir que exista uma lógica de organização por de trás destas relações econômicas, boa parcela dos trabalhadores informais possui longas e regulares jornadas de trabalho (LEONE, 2010; SENA, 2002; QUEIROZ, 2015; IBGE, 
2003), assim como a obtenção da renda média depende de um crescente desgaste e maiores jornadas executadas por estes trabalhadores.

A lógica destas elevadas jornadas e a dificuldade de obtenção de uma maior renda média também se destacam nas possíveis alterações da rotina de trabalho na Feira da Cidade, sendo que para $45 \%$ os horários se modificam devido o maior fluxo de pessoas nas proximidades e dentro da feira, assim nos dias festivos aumenta a demanda e também as jornadas. Bem como o inverso é verdadeiro, nos dias em que o movimento é considerado fraco, pelo número reduzido de pessoas que frequentam a feira, como, por exemplo, nos dias de chuva. Entre os $48 \%$ que disseram não alterar seu horário de trabalho, não modificam por conta de já terem uma jornada de trabalho já muito extensa, como já ressaltaram diversos estudos (SENA, 1999; 2002, LEONE, 2010, CACCIAMALI, 2000).

Os rendimentos no setor informal de feiras são variáveis e a maioria dos entrevistados comentou não fazer nenhum tipo de contabilidade de receita, "tudo é feito na cabeça" e em alguns casos anotados. Os dados levantados apontam um grupo expressivo que auferem rendimentos a cima da média, $42 \%$ admitiram valores acima de $R \$ 550,00$ nos dias de maior pico de atividades, caracterizando uma faixa de feirantes detentores de melhores condições de realização do circuito primário de vendas, não sendo possível, porém, estabelecer que seja uma condição regular os ganhos de pico, na média este segmento aufere rendimento médio nos meses normais de $R \$ 2421,4 \mathrm{e}$ nos meses de maior movimento de $\mathrm{R} \$ 3114,5$ reais. Assim, os rendimentos mensais são distribuídos nas seguintes faixas: $10 \%$ respondeu receber menos de um salário mínimo, $21 \%$ declarou receber mais de 5 salários, $31 \%$ de 1 a 2 salários e $38 \%$ de 3 a 5 salários mínimos.

Sena (2002, p. 150), em seus resultados mostrou que dezembro era o mês mais dinâmico para os vendedores ambulantes, pois estava associado a datas comemorativas que aumentavam o fluxo de pessoas nas ruas. Para os feirantes de Ananindeua essa máxima também é verdadeira, pois $63 \%$ dos participantes declararam que o mês de dezembro é o mês de maior movimento para seus negócios, por conta do volume maior de fregueses que frequentam a Feira da Cidade, sendo que para $28 \%$ deles outubro é o mês de maiores rendimentos, em razão do Círio de Nazaré. 
Portanto, diante das informações obtidas observou-se que os rendimentos dos trabalhadores da Feira da Cidade são mais altos do que os vencimentos básicos de ocupações formais de nível médio. Todavia, existem trabalhadores que recebem menos de um salário mínimo e que estão em condições de maior precariedade e incerteza nas relações de trabalho, pois não sendo os donos do negócio precisam aceitar as difíceis condições de ocupação no setor informal.

\section{CONSIDERAÇÕES FINAIS}

A pesquisa realizada denotou muitos aspectos inusitados e fundamentais para continuidade dos estudos sobre a informalidade e, muito especificamente, sobre o "burburinho das feiras". A informalidade é um fenômeno complexo, assim como as condições de desenvolvimento do capitalismo em sociedades periféricas. Aspecto relevante constatado é que a informalidade, tal como condição ocupacional, não é algo transitório, sendo que parcela considerável dos feirantes $(75,9 \%)$ exercem esta atividade há mais de dez anos. Constatou-se, também, que a renda média de parcela dos feirantes $(21 \%)$ é superior a cinco salários mínimos, uma renda relativamente elevada para os padrões desiguais e espoliativos da sociedade brasileira.

Vale lembrar que a feira é um sistema de economia mercantil simples, possui sua própria dinâmica de funcionamento interna, no qual se observou estratos superiores que detinham uma dinâmica de rendimento liquido diferenciado, por mais que $79 \%$ dos feirantes estejam num padrão de renda menor que cinco salários mínimos, e ainda, na totalidade se ocupem em jornadas de trabalho muito elevadas (acima de dez horas diárias) durante os sete dias da semana. Os ramos que mais auferem renda são aqueles de mercadorias que suprem uma demanda tanto interna (própria feira, feirantes como clientes) como externa (clientes de fora, fregueses).

Através da convivência com os feirantes durante os dias de pesquisa, identificou-se a importância do comércio formal nos arredores da Feira, pois os trabalhadores formais costumam lanchar, comprar seus produtos de subsistência dentre outros na feira mais próxima deles. Evidenciando um fluxo de renda existente, que sai do formal ao informal e vice-versa, ou seja, quanto mais lojas abrem nos arredores, 
melhor é para os negócios dos feirantes, comprovando a validade dos argumentos sobre a relação formal-informal descrita por Sena (2002), Cacciamali (2000) e Oliveira (1988), adaptados ao seguimento de feiras no município de Ananindeua. Como parte do padrão aqui teorizado de economia mercantil simples, ou seja, os trabalhadores explorados no sistema formal capitalista trocam parte do valor da sua força de trabalho por mercadorias ou produtos do segmento informal, esta lógica estabelece a totalidade sistêmica: formal e informal são elementos estruturais do capitalismo periférico.

O funcionamento das relações de trabalho na feira é bastante complexo, pois envolve variáveis não mensuráveis de caráter subjetivo, o presente trabalho foi um esforço de buscar aliar a teoria econômica e os aspectos do cotidiano, da sistemática das relações econômicas na sociedade, visando a elucidação das principais características das relações de trabalho na Feira da Cidade, mostrando a realidade econômica dos feirantes.

\section{REFERÊNCIAS BIBLIOGRÁFICAS}

ALEMIDA, Paulo Roberto de. A crise econômica internacional e seu impacto no brasil. 13 de setembro de 2009. Disponível em:

$<$ http://www.institutomillenium.org.br/artigos/a-crise-economica-internacional-e-seuimpacto-no-brasil/>. Acesso em: 19/07/2017.

BLOG MEIA DOIS NOVE. Arquitetura e consultoria. Disponível em <http://meiadoisnove.blogspot.com.br/2012/08/feira-da-cidade-ananindeua-para.html>. Último acesso em 25/02/2018

CACCIAMALI, M. C. Globalização e processo de informalidade. Economia e Sociedade, v. 14, 2000.

C. M. de Oliveira Pimentel Junior Indira Cavalcante da Rocha Marques Waldemar Sobral Sampaio, "FEIRAS EM BELÉM DO PARÁ: UM ESTUDO A PARTIR DOS PRESSUPOSTOS DO PARADIGMA DA CONCORRÊNCIA PERFEITA," 2017.

Economia Informal Urbana IBGE 2003. Disponivel em < https://biblioteca.ibge.gov.br /index.php/biblioteca-catalogo?view=detalhes\&id=283545>. Último Acesso em 25/02/2018.

FIEL, Ewerton Uchôa Vieira. Relações informais de trabalho: um estudo de caso dos trabalhadores por conta própria das feiras da cidade em Ananindeua-PA / Ewerton Uchôa Vieira Fiel; Orientador José Raimundo Barreto Trindade. - Belém, 2018. Disponível em: https://opamet.com.br/wp49/monografias-dissertacoes-e-teses/. 
FILÁRTIGA, Gabriel Braga. Custos de transação, instituições e a cultura da informalidade no Brasil. Revista do BNDES, Rio de Janeiro, v. 14, n. 28, p. 121-144, 2007.

GODOY, Wilson Itamar; DOS ANJOS, Flávio Sacco. O PERFIL DOS FEIRANTES ECOLÓGICOS DE PELOTAS-RS. Revista Brasileira de Agroecologia, v. 2, n. 1, 2007.

JAKOBSEN, Kjeld et al. Mapa do trabalho informal. Editora Fundacao Perseu Abramo, São Paulo Google Scholar, 2000.MEMORIAL DESCRITIVO DA FEIRA DA CIDADE. Disponível em: <http://www.meiadoisnove.com.br/memorial feiradacidade.pdf>. Último acessado em 25/02/2018.

KREIN, J. D. \& PRONI, M. W. Economia informal: aspectos conceituais e teóricos. OIT, 2010.

LEONE, Eugenia Troncoso. O perfil dos trabalhadores e trabalhadoras na economia informal. ILO, 2010.

MARINI, Ruy Mauro. Subdesenvolvimento e Revolução. 6 ed. Florianópolis: Editora Insular, 2013.

MEMORIAL DESCRITIVO DA FEIRA DA CIDADE, disponível em < https://goo.gl/isas5e > Último acesso em 06/03/2018.

MICRO, SERVIÇO BRASILEIRO DE APOIO ÀS. Participação das micro e pequenas empresas na economia brasileira. Brasília. Disponível em http:Ilwww.sebrae.com. br.SebraePortal\% 20SebraeEstudos\% 20e, v. 20, 2014.

Observatório do trabalho do Estado do Pará - OPAMET. MATHIS, M.; ROMEU, Formalidade e Informalidade no Brasil e Pará nas últimas duas décadas. Texto de discussão n 04.2016.

OIT. El trabajo decente y la economia informal. OIT, 2002.

OLIVEIRA, F. Crítica à Razão Dualista. São Paulo: Vozes (1988).

OLIVEIRA, Marcio André Araújo de. Trabalho Informal e Redes Sociais: os camelôs da Praça da Matriz em Manaus. 2016. Tese de Doutorado. Dissertação (Mestrado em Sociologia). Programa de Pós-Graduação em Sociologia da Universidade Federal do Amazonas. 2009. Disponível em:< http://ppgsocio. ufam. edu. br/attachments/024_M\% C3\% A1rcio\% 20Andr\% C3\% A9\% 2 0Ara\% C3\% BAjo\% 20de\% 20Oliveira. pdf>. Acesso em: 31 jan. 
PINHEIRO, Alessandro Maia; ÁLVARO, Maria Angela Gemaque. INFORMALIDADE NA REGIÃO METROPOLITANA DE BELÉM: UM RETRATO POR GÊNERO.

PEREIRA, Luiza Bresser. Economia brasileira: uma introdução crítica. $12^{\circ} \mathrm{ed}$, Brasiliense, 1994.

QUEIROZ, A. F. Informalidade territórios de trabalho em Salvador. CONINTER, 2014.

RAMOS, Lauro. A evolução da informalidade no Brasil metropolitano: 1991-2001. 2002. ROCHA, Hélio Carlos et al. Perfil socioeconômico dos feirantes e consumidores da Feira do Produtor de Passo Fundo, RS. Ciência Rural, v. 40, n. 12, 2010.

SANTOS, Geórgia Patrícia Guimarães dos et al. Desemprego, informalidade e precariedade: a situação do mercado de trabalho no Brasil pós-1990. Pro-posições, 2008.

SENA, A. Laura. Dimensões da informalidade Em Belém. Novos cadernos do NAEA. v.2, n² - dezembro 1999.

SENA, Ana Laura. O Trabalho informal nas ruas e praças de Belém: Estudo sobre o comércio ambulante de produtos alimentícios. Belém: NAEA, 2002.

SUISSO, Flávia. Trabalho informal no Brasil contemporâneo. Revista eletrônica da Faculdade de Direito de Campos, 2006.

THEODORO, M. As características do mercado de trabalho e as origens do informal no Brasil. In: SILVA, F. B. da [etal.] [org.]. Questão social e políticas sociais no Brasil contemporâneo. Brasília: Ipea, 2005.

TRINDADE, J. R. B. A metamorfose do trabalho na Amazônia. Belém: Editora da UFPA/NAEA, 2001.

VASCONCELOS, E. \& TARGINO, I. A informalidade no mercado de trabalho brasileiro (1993-2013). Revista da ABET, V. 14, N. 1, 2015.

VEDANA, Viviane. " Fazer a Feira": estudo etnográfico das" artes de fazer" de feirantes e fregueses da Feira Livre da EPATUR no contexto da paisagem urbana de Porto Alegre. 2004.

JORDÃO, A. P. F; STAMPA, I. T.VII Jornada internacional de políticas públicas, PRECARIZAÇÃO E INFORMALIDADE NO “MUNDO DO TRABALHO” NO BRASIL: Notas para reflexão. 2015. 